COPYRIGHT @ 2018 INTERNATIONAL JOURNAL OF SCIENCE DENTISTRY | AVAILABLE ONLINE

http://www.periodicos.uff.br/index

\title{
IMPLICAÇÕES ODONTOLÓGICAS DO BULLYING NA ADOLESCÊNCIA
}

DENTAL IMPLICATIONS OF BULLYING IN ADOLESCENCE

Sérgio Spezzia*

Cirurgião Dentista. Especialista em Adolescência para Equipe Multidisciplinar e Mestre em Pediatria e Ciências Aplicadas à Pediatria pela Escola Paulista de Medicina Universidade Federal de São Paulo.

Categoria do trabalho: Artigo de Revisão de Literatura.

\section{Autor Principal:}

Sérgio Spezzia

Rua Silva Bueno, 1001

São Paulo - SP

CEP: 04208-050

Tel. (11) 96925.3157

Email: sergio.spezzia@unifesp.br 


\section{Resumo}

Bullying consta de transgressão que envolve muito comumente adolescentes, principalmente em suas escolas, o que impacta desfavoravelmente no funcionamento social, qualidade de vida e no bem estar desses indivíduos. Nessa situação oriunda de desigualdade de poder, desnecessariamente, empreende-se comportamento persistente, dotado de agressividade, visando ocasionar prejuízo moral ou de caráter físico. Existem situações clínicas em que a estética mostra-se prejudicada na saúde bucal, o que pode desencadear ocorrência do bullying. $\mathrm{O}$ objetivo da presente pesquisa foi por intermédio de um estudo de revisão bibliográfica investigar como as manifestações clínicas provenientes da saúde bucal repercutem na ocorrência de bullying na adolescência. Comumente repercutem, causando bullying situações que apresentam estética prejudicada ou pobre, tais como: má oclusão; apinhamento dental com overjet e overbite; dentes restaurados com aparência estética ruim ou com cor diferenciada visíveis em região anterior da boca; hipoplasia do esmalte, incluindo outros defeitos ou anomalias que podem ocasionar alteração da cor do esmalte e estética prejudicada; presença de múltiplas lesões de cárie visíveis, comprometendo a aparência física do jovem, dentre outros. Concluiu-se que o papel desempenhado pelo cirurgião dentista é fundamental para a elaboração de um plano de tratamento odontológico adequado com diagnóstico e prognóstico voltados para resolução dos problemas dentários que afligem a estética bucal dos adolescentes vitimados pelo bullying.

Palavras-chave: Bullying. Adolescente. Comportamento do Adolescente. Saúde Bucal. Qualidade de Vida.

Keywords: Bullying. Adolescent. Adolescent Behavior. Oral Health. Quality of Life. 


\section{INTRODUÇÃO}

A fase da adolescência, devido as transformações físicas, sociais, biológicas, emocionais, comportamentais e psicológicas que vão ocorrendo, repercute, mantendo determinados conceitos firmados pelos adolescentes pelo restante de suas vidas. Nesse período também ocorre a estruturação do caráter e da identidade, que é mantida e perpetuada da mesma forma. Medo, inquietação, depressão e ansiedade também podem estar presentes (GATTO, 2015).

Nesse período têm-se transformações corpóreas, bem como modificações na forma de proceder do adolescente. Verifica-se mudanças nos hábitos alimentares, nas relações sociais, familiares e culturais, entre outras. Nessa fase da vida os indivíduos jovens podem mostrar-se em situação de vulnerabilidade e de risco, uma vez que é nela que os adolescentes desenvolverão seu comportamento de vida. Os riscos podem trazer consequências graves para o futuro e podem impactar desfavoravelmente na qualidade de vida desse público (ANDRADE et al., 2012).

Sabe-se que qualidade de vida mostra-se intrínsecada ao bem estar e a autoestima das pessoas, abrangendo ainda outras características influenciadoras que são próprias de cada um, tais como: autocuidado; estilo de vida; situação de saúde e financeira; convívio social; estado emocional, entre outras. Nos adolescentes, mais especificamente, essa qualidade de vida correlaciona-se com a subjetividade, a saúde mental e o seu bem estar (GASPAR et al., 2006).

Nesse contexto, muitos estudos denotam que as condições bucais presentes nos indivíduos mostram relação direta com suas qualidades de vida (LOPES et al., 2009, ARAÚJO et al., 2010).

O convívio social e as relações de amizade detém papel de destaque para os adolescentes e algumas opiniões de determinados amigos são consideradas. Em contrapartida, quando houver relacionamentos de amizade conflituosos, que ocasionam violência e/ou humilhações diversas, têm-se o acometimento por problemas de ordem emocional e comportamental (GATTO, 2015).

Em termos de Saúde Coletiva essa situação vivenciada de violência impacta negativamente no desenvolvimento dos adolescentes, causando prejuízos em sua condição de vida e qualidade de vida (PAULA JÚNIOR et al., 2009).

Relacionado a imagem corporal, têm-se preocupação aumentada com a estética e sabe-se que a convivência com uma estética pobre gera problemas desse público jovem para com o convívio social, podendo ocasionar insatisfação de alguns outros, que podem empreender bullying para com os colegas (GATTO, 2015). A estética ou aparência dentária é extremamente valorizada na adolescência e pode gerar da mesma forma, a ocorrência de bullying (BOFFI; FRANZIN, 2017).

O objetivo da presente pesquisa foi por intermédio de um estudo de revisão bibliográfica investigar como as manifestações clínicas provenientes da saúde bucal repercutem na ocorrência de bullying na adolescência. 


\section{REVISÃO DE LITERATURA}

Segundo Camargo, (2016), o termo bullying é oriundo da palavra inglesa bully, que possui significado de "brigão", "valentão".

Atualmente, o bullying tem sido amplamente pesquisado ou estudado no meio científico, constando de transgressão que envolve muito comumente crianças e adolescentes, principalmente em suas escolas, o que impacta desfavoravelmente no funcionamento social, na qualidade de vida e no bem estar desses indivíduos. Nessa situação oriunda de desigualdade de poder, desnecessariamente, empreende-se comportamento persistente, dotado de agressividade, visando ocasionar prejuízo moral ou de caráter físico frente aos indivíduos considerados mais fracos ou impossibilitados de defesa, que convivem socialmente com os outros (BOFFI; FRANZIN, 2017).

$\mathrm{O}$ bullying configura grande problema de cunho social, que prejudica a qualidade de vida dos adolescentes afligidos, ocasionando em decorrência danos com certa gravidade (KLOMEK et al., 2013; ZETTERQVIST et al., 2014).

Estudos realizados em vários países do mundo voltados para análise da ocorrência de bullying no público adolescente demonstraram que a prevalência de bullying oscila entre $5,4 \%$ e $32,6 \%$ e que geralmente têm-se sintomas como baixa autoestima, depressão, ansiedade, suicídio e evasão escolar (PIZARRO; JIMENEZ, 2007).

Baixos níveis de autoestima; insegurança; autoimagem negativa; dificuldades emocionais; nível de estresse elevado; prejuízo no aprendizado escolar; depressão; angústia psicológica; solidão; infelicidade; vergonha; autolesão; isolamento social e tentativa de suicídio, entre outros nos adolescentes correlacionam-se a ocorrência de bullying. O bullying praticado ocasionará nesses adolescentes comportamento social inibido, passivo ou submisso. Ocorre que esses mesmos adolescentes em idade adulta poderão continuar apresentando problemas em decorrência do trauma sofrido no passado, tornando-se indivíduos dotados de baixa autoestima; comportamento agressivo e que podem vir a tentar cometer suicídio (KOWALSKI; LIMBER, 2013; HONG et al., 2015).

É de extremada importância que sejam adotadas medidas efetivas, visando reduzir a ocorrência desenfreada do bullying, uma vez que sua prática repercute desfavoravelmente na saúde geral dos adolescentes, devido aos intempéries causados (UNICEF, 2011).

Classifica-se o bullying sob três formas: com comportamentos diretos e físicos, diretos e verbais e indiretos. Na primeira situação, diretos e físicos pode ocorrer ou haver ameaça de realização de determinados malefícios para outrem, como: agressão física; causar dano ou furtar objetos dos outros, geralmente material escolar em ambiente escolar; extorquir dinheiro; obrigar o colega a obedecer contra sua vontade e a fazer atividades de trabalho para si próprio; comportamentos com cunho sexual obrigatórios, entre outros. Na segunda com comportamentos diretos e verbais incidem atos de insultar; apelidar; promover comentários homofóbicos, racistas ou que façam menção à presença de diferenças para com os outros colegas. Na terceira têm-se manipulação da vida social dos outros colegas; exclusão da pessoa de determinados grupos, buscando benefícios para si próprio e tece-se fofocas e boatos (HONG et al., 2015). 
Em âmbito odontológico e oriundo de repercussões de manifestações clínicas próprias de cada qual pode haver bullying. Adolescentes que detém alterações buco dentais e faciais sofrem desse problema. Comumente repercutem, causando bullying situações que apresentam estética prejudicada ou pobre, tais como: má oclusão; apinhamento dental com overjet e overbite; dentes restaurados com aparência estética ruim ou com cor diferenciada visíveis em região anterior da boca; hipoplasia do esmalte, incluindo outros defeitos ou anomalias (hipomineralização molar incisivo) que podem ocasionar alteração da cor do esmalte em determinados pontos ou localizações específicas ao longo da superfície vestibular dos dentes com estética prejudicada; presença de múltiplas lesões de cárie visíveis na região anterior da boca, comprometendo a aparência física do jovem, dentre outros (BRITO; OLIVEIRA, 2013; BOFFI; FRANZIN, 2017).

A má oclusão, que pode ser alvo de bullying e que pode ser considerada também motivo para estereótipo físico, devido o desvio de padrão estético inerente, constitui um problema de Saúde Pública, advindo de possuir prevalência elevada e ocasionar uma enormidade de transtornos, comprometendo o bem estar e a qualidade de vida. $\mathrm{O}$ apinhamento dental igualmente acarreta problemas acerca do bem estar e qualidade de vida, entretanto, quando inicia-se intervenção ortodôntica, a ocorrência de bullying é minimizada. Nesse contexto, a estética dental age aprimorando o convívio social, melhorando a autoestima e a autoconfiança, dessa forma o tratamento odontológico empregado nos adolescentes acometidos por bullying faz-se importante e configura como auxiliar na resolução de outros problemas, como os de cunho psicológico que possam vir a acontecer (BOFFI; FRANZIN, 2017).

O tratamento ortodôntico sob o enfoque dos pais auxilia na melhora da saúde bucal e na autoestima dos seus filhos. Em conformidade com Kiyak, (2008), o emprego da terapia ortodôntica em adolescentes é capaz de produzir estética dental aprimorada e bem estar, minimizando episódios de bullying.

Uma saúde bucal satisfatória com inclusão de elementos estéticos dentais favoráveis evita episódios de bullying e possui papel de destaque, uma vez que possibilita melhora na autoconfiança, autoestima, bem estar e na qualidade de vida. A reabilitação oral, nesse mesmo contexto, pode ainda atuar, aperfeiçoando a fonação, a capacidade mastigatória, podendo preventivamente agir para que más oclusões não se instalem (SEEHRA et al., 2013).

Relacionado ao tratamento odontológico proporcionado por equipe multidisciplinar, deve haver integração entre profissionais de algumas especialidades, tais como: Odontopediatria, Ortodontia, Prótese Dentária, Dentística e Implantodontia para que seja possível o restabelecimento funcional e estético nos adolescentes. Muitas vezes a continuidade da realização do tratamento odontológico depende do feitio de um procedimento anterior, este que pode requerer algum período de tempo para surtir efeito, muito comumente ocorre esse tipo de manifestação quando têm-se tratamento ortodôntico envolvido, portanto, para que ocorra resolução efetiva dos casos, faz-se necessário firmar um planejamento odontológico e ir-se realizando as intervenções odontológicas, uma a uma, passo a passo, respeitando-se o intervalo de tempo pertinente para que cada tratamento em cada especialidade odontológica surta efeito desejável (BEZERRA et al., 2007). 


\section{DISCUSSÃO}

Existem alguns possíveis estereótipos, desencadeadores de bullying que não são Condizentes com o perfil encontrado comumente entre os indivíduos e que podem gerar discriminação. A má oclusão pode ser considerada um estereótipo, como exemplo a nível odontológico (BOFFI; FRANZIN, 2017).

Convém salientar, que o tratamento ortodôntico traz consigo alguns benefícios que podem auxiliar em muito nos casos de bullying em adolescentes, uma vez que propicia correção estética, podendo minimizar episódios de ansiedade (FEU et al., 2012).

Episódios de violência física e verbal são muito frequentes em escolas de ensino fundamental e médio, ocorre que esse fato pode agir, ocasionando problemas no que tange ao desenvolvimento comportamental dos adolescentes, esse tipo de ocorrência deve ser evitado e tem assumido caráter prioritário nas discussões voltadas para a área dos problemas de Saúde Pública (BOFFI; FRANZIN, 2017).

Segundo Gatto, (2015), a aparência dental correlaciona-se a autoestima, pois quando temos estética dentária insatisfatória teremos baixa autoestima.

A maioria dos indivíduos acredita que o aperfeiçoamento da aparência relacionada com a estética dos dentes faz parte dos requisitos básicos para melhor desempenho ou convívio social, servindo para aguçar a autoestima.

No ambiente escolar podem ocorrer também comportamentos indesejados que se diferenciam do bullying, em decorrência disso, faz-se importante distinguir bullying de brincadeiras em que todos envolvidos participam, interagem e sentem-se bem; de comportamentos antissociais e de agressividade e indisciplina. Em contrapartida, averigua-se que tais atos não são continuados, não visam intimidar outrem e não afligem uma vítima que fica incapacitada de defender-se (BRITO; OLIVEIRA, 2013).

O relacionamento salutar entre pais e filhos será capaz de formalizar nos adolescentes e nas crianças determinada resistência quando estiverem frente a episódios de bullying. Os pais devem ater-se a seus filhos, dando amparo as suas necessidades básicas, atribuindo-lhes cuidado, confiança e segurança, visando aprimoramento de sua autoestima. Sabe-se que na ausência dessa situação e existindo contato deficitário entre pais e filhos, têm-se maior risco para ocorrer bullying. Os filhos devem ser orientados de forma a decidirem seus atos sozinhos, o que possibilita a estruturação de sua própria autonomia, entretanto, sempre levando em consideração parâmetros normativos de responsabilidade e de regras, dessa forma quando depararem-se com situações como as ocasionadas pelo bullying, poderão enfrentá-las. Um reflexo favorável desse tipo de atitude dos pais, onde existe toda dedicação e cuidado necessários repercute satisfatoriamente na manutenção da saúde bucal, uma vez que se mostram desenvolvidos nos filhos autocuidado e autoestima, bem como hábitos de responsabilidade, o que irá propiciar por conseguinte, hábito de realização de higiene bucal de forma correta, rotineiro e que surta resultado (HOZ-AIZPURUA et al., 2011).

De acordo com Hoz-Aizpurua et al., (2011), episódios de bruxismo noturno e de bullying escolar acometem, concomitantemente os adolescentes e detém importância extremada por influírem nas condições e na qualidade de vida dos mesmos. Escalas para aferição da satisfação de vida tem sido instituídas, devido ao fato, visando empreender 
COPYRIGHT @ 2018 INTERNATIONAL JOURNAL OF SCIENCE DENTISTRY | AVAILABLE ONLINE

http://www.periodicos.uff.br/index

avaliação cognitiva da vida, tomando como base padrões avaliativos, escolhidos pelo próprio indivíduo em questão.

\section{CONCLUSÃO}

Concluiu-se que o papel desempenhado pelo cirurgião dentista é fundamental para a elaboração de um plano de tratamento odontológico adequado com diagnóstico e prognóstico voltados para resolução dos problemas dentários que afligem a estética bucal dos adolescentes vitimados pelo bullying.

\section{REFERÊNCIAS}

1 - Gatto RCJ. Bullying e má oclusão relacionados a autoestima e qualidade de vida em adolescentes. [Tese]. Araçatuba: Faculdade de Odontologia de Araçatuba Universidade Estadual Paulista Júlio de Mesquita Filho - UNESP, 2015.

2 - Andrade SSCA, Yokota RTC et al. Association between physical violence, consumption of alcohol and other drugs, and bullying among Brazilian adolescents. Cad Saude Publica, 2012; 28(11):1725-36.

3 - Gaspar T, Matos M et al. Qualidade de vida e bem-estar em crianças e adolescentes. Rev Bras Terapias Cognitivas, 2006; 2(2):47-60.

4. Lopes MWF, Gusmão ES et al. The impact of chronic periodontitis on quality of life in brazilian subject. Acta Stomatol Croat, 2009; 43 (2):89-98.

5 - Araújo ACS, Gusmão ES et al. Impact of periodontal disease on quality of life. Quintessence Int, 2010; 41:e111-e118.

6 - Paula Júnior DF, Santos NCM et al. Psychosocial impact of dental esthetics on quality of life in adolescents. Angle Orthod. 2009; 79:1188-93.

7 - Boffi JC, Franzin LCS. Bullying e a Atuação da Odontologia. Rev Uningá Review, 2017; 29(2):38-41.

8 - Camargo O. Bullying. Brasil Escola. Disponível em: https://brasilescola.uol.com.br/sociologia/bullying.htm Acessado em 20 de junho de 2018.

9 - Klomek AB, Kleinman M et al. Suicidal adolescents' experiences with bullying perpetration and victimization during high school as risk factors for later depression and suicidality. J Adolesc Health, 2013; 53: 37-42.

10 - Zetterqvist M, Lundh LG et al. A cross-sectional study of adolescent non-suicidal self-injury: support for a specific distress-function relationship. Child Adolesc Psych Mental Health, 2014; 8:23.

11 - Pizarro HC, Jimenez MI. Maltratos entre iguales em La escuela costarricense. Rev Educa, 2007, 31(1):135-44.

12 - Kowalski RM, Limber SP. Psychological, physical, and academic correlates of cyberbullying and traditional bullying. J Adolesc Health, 2013; 53:S13-20.

13 - Hong JS, Kral MJ et al. Pathways from bullying perpetration, victimization, and bully victimization to suicidality among school-aged youth: a review of the potential 
COPYRIGHT @ 2018 INTERNATIONAL JOURNAL OF SCIENCE DENTISTRY | AVAILABLE ONLINE

http://www.periodicos.uff.br/index

mediators and a call for further investigation. Trauma, Violence \& Abuse, 2015; 16:379-90.

14 - Unicef. O direito de ser adolescente: Oportunidade para reduzir vulnerabilidades e superar desigualdades. Brasília, DF; UNICEF, 2011.

15 - Brito CC, Oliveira MT. Bullying and self-esteem in adolescents from public schools. J Pediatr, 2013; 89(6):601-7.

16 - Kiyak HA. Does orthodontic treatment affect patient's quality of life? J Dent Educ, 2008; 72(8):886-94.

17 - Seehra J, Newton JT et al. Interceptive orthodontic treatment in bullied adolescents and its impact on selfesteem and oral-health-related quality of life. Eur J Orthod, 2013; 35(5):615-21.

18 - Bezerra F, Meireles JK et al. Diagnóstico e tratamento de ausências dentárias na região maxilar causadas para agenesia de incisivos laterais. Rev lmplantnews, 2007; 4(2):141-5.

19 - Feu D, Oliveira BH et al. Influence of orthodontic treatment on adolescents' selfperceptions of esthetics. Am J Orthod Dentofacial Orthop, 2012; 141(6):743-50.

20 - Hoz-Aizpurua JL, Alonso ED et al. Sleep bruxism. Conceptual review and update. Med Oral Patol Oral Cir Bucal, 2011,16 (2):231-8. 